Published in final edited form as:

Am J Geriatr Psychiatry. 2019 October ; 27(10): 1083-1096. doi:10.1016/j.jagp.2019.04.019.

\title{
Particulate air pollutants and trajectories of depressive symptoms in older women.
}

Andrew J. Petkus, Ph.D. ${ }^{1}$, Diana Younan, Ph.D. ${ }^{2}$, Xinhui Wang, Ph.D. ${ }^{1}$, Marc Serre, Ph.D. ${ }^{3}$, William Vizuete, Ph.D. ${ }^{3}$, Susan Resnick, Ph.D. ${ }^{4}$, Mark A. Espeland, Ph.D. ${ }^{5}$, Margaret Gatz, Ph.D. ${ }^{6}$, Helena Chui, M.D. ${ }^{1}$, JoAnn E. Manson, M.D., DrPH ${ }^{7}$, Jiu-Chiuan Chen, M.D., ScD ${ }^{1,2}$ ${ }^{1}$ Department of Neurology, University of Southern California

${ }^{2}$ Department of Preventive Medicine, University of Southern California

${ }^{3}$ Department of Environmental Sciences and Engineering, University of North Carolina at Chapel Hill

${ }^{4}$ National Institute on Aging

${ }^{5}$ Department of Biostatistical Sciences, Wake Forest School of Medicine

${ }^{6}$ Center for Economic and Social Research, University of Southern California

${ }^{7}$ Department of Medicine, Brigham and Women's Hospital, Harvard Medical School

\section{Abstract}

Objectives: Although several environmental factors contribute to the etiology of late-life depressive symptoms, the role of ambient air pollution has been understudied. Experimental data support the neurotoxicity of airborne particulate matter with aerodynamic diameter of $\leq 2.5 \mu \mathrm{m}$ $\left(\mathrm{PM}_{2.5}\right)$, but it remains unclear whether long-term exposure is associated with late-life depressive symptoms. Our secondary aim was to explore whether the observed associations between exposure and depressive symptoms are explained by dementia risk.

Design, Setting, and Participants: Prospective community-dwelling cohort study from the Women's Health Initiative Study of Cognitive Aging (1999-2010). Our analyses included 1,989 older women (baseline age 73.3+3.75) with no prior depression or cognitive impairment.

Measurements: Participants completed annual assessments of depressive symptoms (15-item Geriatric Depression Scale). Average ambient $\mathrm{PM}_{2.5}$ exposure at the residential location was estimated by spatiotemporal modeling for the three-years preceding each neuropsychological

Corresponding Authors: Andrew J. Petkus, Ph.D., University of Southern California, Department of Neurology, 1520 San Pablo St., Suite 3000, Los Angeles, CA 90033, Phone: 323-442-8050, petkus@ usc.edu Jiu-Chiuan Chen, MD, ScD, Department of Preventive Medicine and Neurology, Keck School of Medicine, University of Southern California, SSB 225P 2001 N. Soto Street, Los Angeles, CA 90033, Phone: 323-442-2949, jcchen@usc.edu.

Publisher's Disclaimer: This is a PDF file of an unedited manuscript that has been accepted for publication. As a service to our customers we are providing this early version of the manuscript. The manuscript will undergo copyediting, typesetting, and review of the resulting proof before it is published in its final citable form. Please note that during the production process errors may be discovered which could affect the content, and all legal disclaimers that apply to the journal pertain.

Previous Presentation: Portions of this work have been presented previously at the Joint Annual Meeting of the International Society of Exposure Science and the International Society of Environmental Epidemiology taking place August 26 - August 30, 2018, in Ottawa CA. 
assessment. Participants underwent separate annual examinations for incident dementia defined by DSM-IV. Latent-class mixture models examined the association between $\mathrm{PM}_{2.5}$ and identified trajectories of symptoms.

Results: Six trajectories of depressive symptoms were identified. Across all women, $\mathrm{PM}_{2.5}$ exposure was positively associated with depressive symptoms. The effect was especially strong in two clusters with sustained depressive symptoms ( $\mathrm{n}=625$ sustained-mild [31\%]; $\mathrm{n}=125$ sustainedmoderate; [6\%]). Among those with sustained-moderate symptoms, the estimated adverse effect of $\mathrm{PM}_{2.5}$ exposure was greater than that of hypertension. Among women without dementia, associations were modestly attenuated.

Conclusions: Long-term exposure to ambient fine particles was associated with increased depressive symptoms among older women without prior depression or cognitive impairment.

\section{Keywords}

depressive symptoms; air pollution; epidemiology

\section{Objective}

Late-life depressive symptoms are common, disproportionally affect women (1), impair functioning and quality of life, and are a significant burden to public health (2), even when the total number of symptoms does not meet criteria for a clinical diagnosis (3). Etiologies of depressive symptoms that emerge in later life (after age 65) likely differ from the causes of mood symptoms with an earlier-life onset (4). Both clinical and epidemiologic data has shown that late-life depression is heterogenous in nature with multiple contributing factors including cerebrovascular disease (5), neurodegeneration, and medical comorbidities (6). While twin studies suggest that late-life depressive symptoms are heritable, environmental factors explain the majority of the variance (7). However, there has been limited longitudinal environmental epidemiologic research on depressive symptoms that considers the distinct trajectories of symptoms over time (8). Previous research largely focused on psychosocial factors and depressive symptoms (9), and the potential role of physical environments has been understudied.

There is increasing evidence that ambient air pollutants, especially fine particulate matter $\left(\mathrm{PM}_{2.5}\right.$; aerodynamic diameter $\left.<2.5 \mu \mathrm{m}\right)$, is associated with accelerated brain aging (10). For instance, late-life exposure to $\mathrm{PM}_{2.5}$ was associated with increased risk for dementia among older women in the US (11). Experimental models also demonstrate airborne particle exposure can accelerate the neurodegenerative processes (11-13). Although neurotoxicological studies have shown depressive-like behaviors in mice exposed to particles (14-16), convincing epidemiologic data are lacking. Few longitudinal studies have examined the long-term associations between $\mathrm{PM}_{2.5}$, depressive symptomatology and onset of depression, but findings were mixed (17-20). These studies suffered from major methodological weaknesses, including short follow-up time with only two repeated assessments $(18,19)$, ignoring the heterogeneity in trajectories of depressive symptoms over time (18-20), utilizing medical records for the ascertainment of depression $(17,20)$, and inadequate control of potential confounders (20). Past research has not excluded individuals 
with a past history of depression so results may be biased due to potential confounding by other environmental exposure that have affected emotional health before the study baseline (19). Lastly, no published data has offered insights into the possible mechanistic pathways underlying the hypothesized associations.

Here, we conducted a longitudinal study to examine the association between air pollution and late-life depressive symptoms assessed annually (1999-2010) in a geographicallydiverse sample of community-dwelling older women without prior depression or cognitive impairment. Our primary aim was to investigate whether long-term exposure to $\mathrm{PM}_{2.5}$ in late-life affected the trajectories of depressive symptoms, while rigorously controlling for potential confounders. We hypothesized that exposure to $\mathrm{PM}_{2.5}$ will be positively associated with depressive symptoms in later life. Our secondary aim was to explore whether any associations between exposure and depressive symptoms may be explained by dementia risk, regional brain volumes, or magnetic resonance imaging (MRI) measures of cerebrovascular damage that are known to be associated with $\mathrm{PM}_{2.5}$ exposure and/or depressive symptoms in late life. We hypothesized that dementia risk, regional brain volumes, and MRI measures of cerebrovascular damage would partially explain any putative associations between $\mathrm{PM}_{2.5}$ exposure and late life depressive symptoms.

\section{Methods}

\section{Study Population}

This study included 1,989 community-dwelling older women (aged 73.3 \pm 3.8 years old at baseline) without prior depression or dementia who were enrolled in the Women's Health Initiative Study of Cognitive Aging (WHISCA; $n=2,304$ ) (21), an ancillary study to the Women's Health Initiative Memory Study (WHIMS) (22) which was an ancillary study to the Women's Health Initiative Hormone Clinical Trial (23). These women completed annual (1999-2010) neuropsychological assessments, beginning on average three years after randomization in the Women's Health Initiative hormone therapy trial. Excluded from the present study (see Figure 1) were women who reported a history of depression ( $\mathrm{n}=221)$ before the initial WHISCA assessment and those with missing data on covariates of interest $(\mathrm{n}=92)$. Our analyses also included a subsample of WHISCA participants ( $\mathrm{n}=947)$ who underwent a single brain MRI scan in the Women's Health Initiative Memory Study-MRI (WHIMS-MRI) study between 2005-2006 (24). A detailed description of these original study cohorts was given in the Supplemental Methods. This study was approved by the institutional review boards at all institutions and all participants provided written informed consent.

\section{Assessment of depressive symptoms}

Depressive symptoms were assessed at WHISCA baseline and at each annual follow-up (up to 9 assessments) using the 15 -item Geriatric Depression Scale (GDS-15) $(25,26)$. WHISCA participants were coded as having a past history of depression if they stated yes to both of the depression questions from the National Institute of Mental Health Diagnostic Interview Schedule at the WHIMS baseline that took place between 1996-1999 (27). 


\section{Assessment of ambient $\mathrm{PM}_{2.5}$}

Detailed procedures for $\mathrm{PM}_{2.5}$ estimation have previously been reported $(11,28)$. Briefly, residential addresses were collected at WHI enrollment and at each annual assessment. Standardized protocols (29) were followed for geocoding residential addresses. Daily ambient concentration of $\mathrm{PM}_{2.5}$ at each residential location was estimated using the Bayesian Maximum Entropy-based spatiotemporal modeling method. This approach integrates nationwide monitoring data from the U.S. Environmental Protection Agency Air Quality System and the output of chemical transport models. Estimates of daily $\mathrm{PM}_{2.5}$ exposures were statistically cross-validated (average Pearson's $\mathrm{R}^{2}=.70$ ). The resulting exposure estimates were then aggregated in creating time-dependent estimates of average $\mathrm{PM}_{2.5}$ exposure for the 3-years preceding each respective WHISCA assessment.

\section{Classification of dementia}

Incident cases of all-cause dementia were defined using Diagnostic and Statistical Manual of Mental Disorders, Fourth edition (DSM-4) (30) criteria. Classification of dementia was based on annual screening of cognitive function, neuropsychological and functional assessment, and collection of clinical data to rule out possible reversible causes of cognitive declines through continued WHIMS participation. Annual screenings of all WHIMS participants were completed through administration of the Modified Mini Mental Status (3MS)(31) examination. Beginning in 2008, and continuing to the present, annual cognitive assessment were conducted by telephone using a validated battery $(32,33)$ via participation in the WHIMS-Epidemiology of Cognitive Health Outcomes study.

\section{Structural MRI assessment}

Participants underwent one structural MRI, collected by standardized protocols (24). Measures of brain volume (in $\mathrm{cm}^{3}$ ) included: total volume of normal-appearing white matter, prefrontal grey matter volume, hippocampal volume and total volumes of small-vesselischemic-diseases. These variables were selected because previous studies suggest they were brain areas affected by $\mathrm{PM}_{2.5}$ exposure $(34,35)$ or associated with late-life depression $(5,36)$.

\section{Assessment of covariates}

A structured questionnaire was administered at the WHIMS baseline (between 1996-1999) to gather information on the time-independent covariates of demographics (age, race/ ethnicity), geographic region of residence (Northeast, South, Midwest, and West), socioeconomic status (education; family income; employment status), lifestyle factors (smoking; alcohol use; physical activities), clinical characteristics (postmenopausal hormone treatment, history of CVD (including previous coronary heart, stroke, or transient ischemic attack), hypertension (defined as elevated blood pressure or use of antihypertensive medication), and diabetes mellitus (defined as physician diagnosis plus oral medications, or insulin therapy). Good reliability and validity of the self-reported medical histories and the physical measures have been previously documented (37). Estimates were adjusted for global cognitive ability by including the 3MS (38) as a covariate in all analyses. The 3MS is a reliable and valid measure of global cognitive ability and was administered at the WHIMS baseline assessment. 


\section{Statistical analysis}

Latent class mixed models (LCMM) (39) with a latent process transformation applied to the continuous score of the GDS-15 (to account for non-Gaussian nature of depressive symptoms; see Supplemental Figure 1 for graph of the transformation function) were fit to identify groups of women who had similar trajectories of depressive symptoms over time (See a more detailed description in the Supplemental Methods). A higher score represented more depressive symptoms and the function linking continuous GDS-15 scores to the transformed score is provided in Supplemental figure 1. Years since WHISCA baseline was utilized as the timescale. We started with a base LCMM that included a quadratic function of time (years since WHISCA baseline squared) and attrition (time-dependent covariate if the participant dropped out at the subsequent visit; $0=$ no, 1=yes) as fixed effects to identify the number of classes. We first fit a one-class model and sequentially increased the number of estimated latent classes. The decision of the total number of latent classes to be retained was made by a combination of overall model fit as evidenced by the Bayesian Information Criterion (BIC), the interpretability of the latent classes, the clinical meaningfulness of the class, and how well the latent classes differentiated between participants. See the Supplemental methods for a more detailed description of the approach to decide the number of significant latent classes to retain.

A second series of LCMM analyses were fit to examine the associations between $\mathrm{PM}_{2.5}$ exposure and depressive symptoms. While extracting the same number of latent classes as identified from the base LCMM, we first examined whether $\mathrm{PM}_{2.5}$ exposure had a global effect on the transformed GDS-15 scores, assuming a common exposure effect across all identified trajectories after adjusting for demographic features, socioeconomic status, lifestyle factors, and clinical characteristics. In the subsequent LCMM adjusting for the same set of covariates, the putative association between $\mathrm{PM}_{2.5}$ and depressive symptoms was then re-examined as a class-specific effect, which allowed the association with $\mathrm{PM}_{2.5}$ to vary in magnitude by latent class.

\section{Secondary analyses}

To explore whether dementia risk statistically explained the observed $\mathrm{PM}_{2.5}$ exposure effects, the first set of secondary analyses were conducted only using the data collected in the subsample $(n=1,811)$ who had not developed dementia by December 2015, as determined by standardized protocols and central adjudication (11). Participants were assigned a priori to latent class membership based on the same class membership already determined in the full-sample LCMM with $\mathrm{PM}_{2.5}$ included. We examined the global and class-specific $\mathrm{PM}_{2.5}$ associations and compared the magnitude of these effect estimates to the results from the full model.

Exploratory analyses were further conducted in the WHISCA participants with brain MRI data ( $\mathrm{n}=947)$, to examine whether MRI estimates of structural brain volumes statistically explained the observed association between $\mathrm{PM}_{2.5}$ and depressive symptoms. We examined the global $\mathrm{PM}_{2.5}$ effect in this subsample, as well as the class-specific exposure effect, which was only tested among women belonging to classes with significant associations as 
identified from the primary analyses. Subsequent LCMMs were constructed separately by adding respective MRI variables into the model.

\section{Sensitivity analyses}

Lastly, two additional sets of sensitivity analyses were conducted: 1) using an alternative approach to defining prior depression; and 2) further adjusting for neighborhood socioeconomic characteristics (40) (detailed in the Supplemental methods). All models were fit with the LCMM program (39) in R version 3.5.0 (41).

\section{Results}

\section{Participant characteristics, $\mathrm{PM}_{2.5}$ exposure distribution and trajectories of depressive symptoms}

The majority of these older women ( $\mathrm{N}=1,989$; aged $73.3 \pm 3.8$ years) were Caucasian $(91 \%)$ and had more than a high-school education (74\%). Table 1 compares the distribution of 3year average $\mathrm{PM}_{2.5}$ exposure estimates by population characteristics. Participants exposed to higher levels of $\mathrm{PM}_{2.5}$ were more likely to self-identify as African-American or Hispanic, reside in the Midwest or West, report higher household incomes ( $\$ 75,000)$ or prior histories of cardiovascular disease.

Base LCMM identified six trajectories of depressive symptoms (Supplemental Table 1), including: 779 with minimum GDS-15 scores throughout the study period (39\% minimal), 228 with depressive symptoms emerging early in follow-up (11\% early-emerging), 159 with depressive symptoms increasing during the latter part of the follow-up period (8\% lateemerging), 644 with mildly elevated GDS-15 scores sustained during the follow-up (32\% sustained-mild), 70 starting with elevated GDS-15 scores that decreased over the follow-up (4\% decreasing), and 109 with sustained-moderate GDS-15 scores (5\% sustained-moderate). Figure 2 (panel A) depicts the estimated mean GDS-15 scores over time with 95\% confidence intervals for each latent class. A reference line was included on this graph at a score of 5 or higher to aid in clinical interpretation of these classes as this score is a commonly used cutoff for clinically significant depressive symptoms. Supplemental Figure 2 presents the estimated mean GDS-15 score with individual scores over time. The odds of correct classification were over 5 for all six latent classes, and, with the exception of the late-emerging class $(\mathrm{PP}=.65$ ), had average posterior probabilities over .70 . Table 2 presents the study variables by the six identified latent classes. Clinically meaningful differences between classes were present as women with sustained-mild or sustained-moderate symptoms tended to be in worse physical health with higher proportions of hypertension, cardiovascular disease, and diabetes at baseline, less frequently engaged in moderate or strenuous physical activity, and were more likely to drink alcohol compared to women in other trajectories.

\section{Associations between $\mathrm{PM}_{2.5}$ exposure and GDS trajectories}

Results from the multicovariate-adjusted LCMM analyses are presented in Table 3. In the LCMM including $\mathrm{PM}_{2.5}$ with adjustment for multiple covariates, a six-class solution still provided the best fit to the data. In models estimating the global $\mathrm{PM}_{2.5}$ effect constrained 
across the six identified classes, we found significantly more depressive symptoms ( $\beta=.043$; $p=.039)$ among older women living in locations with elevated $\mathrm{PM}_{2.5}\left(\sim\right.$ by $\left.3.45 \mu \mathrm{g} / \mathrm{m}^{3}\right)$. When examining class-specific effects (all $\mathrm{PM}_{2.5}$ estimates presented in the left panel of Table 3), higher $\mathrm{PM}_{2.5}$ exposure was positively associated with depressive symptoms only in women who had sustained-mild ( $\beta=.096 ; p=.023)$ and sustained-moderate symptoms ( $\beta=$. 171.; $p=.024)$, but the strengths of associations within these two classes were $2-4$ times greater than the estimated global main effect. Figure 2 (panel B) provides the estimated average GDS-15 score among women in the trajectories of sustained-mild or -moderate depressive symptoms, separately by high (upper quartile), median, and low (lower quartile) $\mathrm{PM}_{2.5}$ levels as compared with the corresponding effect estimates of selected covariates (estimated at the mean level of $\mathrm{PM}_{2.5}$ ). Estimated depressive symptoms for women exposed to the median $\mathrm{PM}_{2.5}$ and for those who had diabetes and hypertension at baseline were also plotted to put the $\mathrm{PM}_{2.5}$ effect into the clinical context for comparison. Among those with sustained-moderate symptoms, the magnitude of the adverse $\mathrm{PM}_{2.5}$ effect estimate (per 1interquarile exposure range) was greater than that of hypertension.

\section{Secondary analyses}

Long-term $\mathrm{PM}_{2.5}$ exposure was associated with increased depressive symptoms in the dementia-free sample $(n=1,811)$. Compared to the corresponding LCMM results in the full sample, the estimates of class-specific $\mathrm{PM}_{2.5}$ effects were similar among WHISCA participants without dementia (right panel of Table 3), although the strength of association was slightly diminished and more precise in the subgroup with sustained-moderate depressive symptoms. The global effect estimate was attenuated, but remained statistically significant $(\beta=.038 ; p=.006$ ). Interestingly, the class-specific LCMM also revealed the statistically significant association with $\mathrm{PM}_{2.5}(\beta=.175 ; p<.001)$ among WHISCA participants who had late-emerging depressive symptoms but did not have dementia.

\section{Exploratory analyses}

Among the subsample of WHISCA participants with brain MRI data ( $n=974)$, both the global and class-specific $\mathrm{PM}_{2.5}$ exposure effects were statistically significant (Supplemental Table 2; Model-1). These associations were largely unchanged and remained statistically significant after we further accounted for various MRI-measured regional brain volumes (Supplemental Table 2; Model-2 to Model-5).

\section{Sensitivity Analyses}

In the sensitivity analyses where no prior depression was defined by endorsing clinically significant symptoms, we observed a similar pattern of estimated latent classes (Supplemental Table 3). The same pattern of results emerged in the LCMM that further adjusted for neighborhood socioeconomic characteristics (Supplemental Table 4).

\section{Conclusions}

In this longitudinal study conducted on a geographically-diverse cohort of older women with thorough neuropsychological assessments and no prior depression, we used latent-class mixed models to identify six significant clusters of women who exhibited similar trajectories 
of depressive symptoms assessed annually up to 11-years. Long-term exposure to ambient $\mathrm{PM}_{2.5}$ estimated at the residential locations was associated with increased depressive symptoms, especially among the two clusters of older women who experienced sustainedmild and moderate depressive symptoms. This association was robust after adjusting for multiple potential confounders and other risk factors for late-life depression. Our analyses also showed that dementia risk did not fully explain this association. In a subsample of women who underwent structural brain MRI imaging, differences in their volumetric measures of normal-appearing white matter, prefrontal cortex, hippocampus, and smallvessel-ischemic-disease could not explain the observed increase in depressive symptoms associated with long-term $\mathrm{PM}_{2.5}$ exposure. The neuropathological processes underlying the putative neurotoxic effect of $\mathrm{PM}_{2.5}$ exposure in late life remains elusive, but are damage. likely independent of cerebrovascular damage.

Our study addresses the limitations of previous research on air pollution and emotional health (see Supplemental Table 5) in several ways. Null associations between long-term $\mathrm{PM}_{2.5}$ exposure and depressive symptoms of community-dwelling populations were reported in two longitudinal studies $(18,19)$, one conducted in Boston (aged 265 years) and the other across the U.S. (aged 57-85 years). Neither study excluded individuals with a prior history of depression. This restriction not only ensures the study outcome most relevant to late-life depressive symptoms, but also helps reduce the potential confounding by other environmental exposures (including early/mid-life $\mathrm{PM}_{2.5}$ ) and genetic associations presumably affecting emotional health before the baseline. With the depressed symptoms only assessed twice, investigators were unable to characterize the longitudinal trajectories, thus missing the opportunity to examine the potential heterogeneity of exposure effects. Kim et al. (42) reported that long-term $\mathrm{PM}_{2.5}$ exposure increased the risk of major depression amongst the general population of Seoul, Republic of Korea (15-79 years old). However, participants were followed for two years, and the difference in early-life and late-life depression was disregarded. Only aggregated measures of air pollution exposure were used in their analyses that did not adequately account for confounding by socioeconomic status. Also, their ascertainment for depressive disorders was based on diagnostic codes in medical claims data, an approach known to suffer from outcome misclassification with only modest accuracy (43) and low sensitivity (44). Kioumourtzoglou et al. (17) carefully excluded those with reported prior depression from an US-nationwide cohort of older women (aged 66.6 \pm 7.6 ). Their observed association, however, was sensitive to different outcome definitions and the inclusion of subjects with comorbid conditions presumably associated with late-life depressive symptoms. Although clinical entities of depression often represent arbitrarily defined categories with more extreme manifestations of the continuum of depressive symptoms, the above-mentioned methodological limitations point to the need for future studies with high-quality longitudinal data on outcome (including diagnostic interviews) and comorbidities to examine the association between $\mathrm{PM}_{2.5}$ and depressive disorders.

Our study adds novel data to the emerging field of environmental neurosciences of air pollution and brain aging. Previous studies have shown long-term $\mathrm{PM}_{2.5}$ exposure may increase risk of dementia (10), including our report based on WHIMS data (11). Empirical data from WHISCA also showed that GDS-15 trajectories predicted the risk for dementia 
(data not shown) (45). Taken together, all these data point to two interesting possibilities. First, if late-life depressive symptoms represent a prodromal neuropsychiatric manifestation of dementia (46), findings of the present study suggest that $\mathrm{PM}_{2.5}$ may perturb the common neuropathological processes leading to the trajectories with sustained depressive symptoms and an increased risk for dementia. Second, it is also possible both depressive symptoms and dementia have shared risk factors, and late-life exposure to $\mathrm{PM}_{2.5}$ may represent an example of such common environmental causes acting upon overlapping or distinctive pathways to compromise emotion regulation abilities.

No previous epidemiologic data were available to help elucidate the neural basis of increased depressive symptoms associated with air pollution exposure. In the informative subsample of older women participating in both WHISCA and WHIMS-MRI, we found both the global $\mathrm{PM}_{2.5}$ effect and the class-specific exposure effect (especially among those with sustained-moderate symptoms) remained statistically significant after we further accounted for various MRI-measured regional brain volumes (e.g., prefrontal cortex, normally-appearing white matter) with negative associations with $\mathrm{PM}_{2.5}$ exposure. These results underscore the need for future studies to investigate other brain regions and neural networks vulnerable to the $\mathrm{PM}_{2.5}$ neurotoxicity that may predispose older people to increased depressive symptoms in late life.

The findings in this study have potential important policy and clinical implications. These findings emphasize the importance of enforcing environmental regulations (e.g., the Clean Air Act) and initiatives for other public policies to minimize the adverse impact of ambient air pollutants on older adults. Clinicians might consider air pollution as a possible contributing factor to their patients' depressive symptoms and can provide relevant psychoeducation to their patients.

We recognize several limitations of our study. First, although the $\mathrm{PM}_{2.5}$ spatiotemporal model was statistically cross-validated (average Pearson's $\mathrm{R}^{2}=0.70$ ) (28), the resulting exposure estimates were still subject to measurement errors. However, such estimation errors are likely non-differential and tend to attenuate the observed associations. Second, we only studied $\mathrm{PM}_{2.5}$ exposure as regional air pollutants, with no data on its chemical constituencies, emission sources, or possible interactions with other pollutant mixtures. Third, structural MRI data was only available for a subsample of women in our study and was cross-sectional. Fourth, although the application of the latent process transformation to GDS-15 scores was necessary statistically, the clinical interpretation of our findings may not be straightforward. However, given the informative comparison made between the adverse $\mathrm{PM}_{2.5}$ effect and several clinical comorbidities (Figure 2), we advocate for more use of LCMM with latent process score for studying clinically-relevant questions on late-life depressive symptoms in future research. Fifth, our analyses of brain MRI data were largely based on region-of-interest with only volumetric measures of global regions - an approach that may not have the sufficient sensitivity and specificity to identify areas vulnerable to $\mathrm{PM}_{2.5}$ neurotoxicity or critical to emotion regulation. We only analyzed data from a single structural MRI and thus limits our ability to make inferences about the extent to which $\mathrm{PM}_{2.5}$ exposure is associated with change in structural MRI variables and depressive symptoms over time. Future research needs to utilize repeated MRI measures to examine 
whether there are $\mathrm{PM}_{2.5}$ associated changes in brain volumes based on depressive symptom trajectories. Lastly, future studies should consider high-dimensional analyses, including the use of machine learning (47) that may offer a better approach to understanding the likely complex brain structure and neural networks linking $\mathrm{PM}_{2.5}$ exposure with depressive symptoms in late life.

This study had several major strengths. First, women were followed over a long period up to 11 years with a maximum of nine assessments of their depressive symptoms. Second, we employed the sophisticated LCMM modeling approach, which allowed us to identify the trajectories of depressive symptoms as the basis for examining the heterogeneity of $\mathrm{PM}_{2.5}$ exposure effects. Third, we had access to well-validated data on dementia and MRI-based measures of regional brain volumes and cerebrovascular damage, which enabled the first step to explore the potential contributors to the neuropathological processes linking late-life exposure to $\mathrm{PM}_{2.5}$ with GDS-15 trajectories. Lastly, the rich, comprehensive covariate data from the WHIMS cohort offered a unique population context for optimal study design that excludes individuals with prior depression and rigorously assess and adjust for potential confounding.

In conclusion, among older women with no prior depression or dementia, long-term exposure to ambient fine particles is a novel environmental risk factor for sustained depressive symptoms, independent of other known risk factors for late-life depression. Future studies need to better understand the biological underpinnings of this association.

\section{Supplementary Material}

Refer to Web version on PubMed Central for supplementary material.

\section{Acknowledgments:}

For a list of all the investigators who have contributed to WHI science, see: https://www.whi.org/researchers/ Documents\%20\%20Write\%20a\%20Paper/WHI\%20Investigator\%20Long\%20List.pdf

Lastly, we are appreciative of Drs. Cécile Proust-Lima and Viviane Philipps for their helpful suggestions for fitting Latent Class Mixture Models with a-priori group assignment.

All sources of support:

The WHIMS was funded by Wyeth Pharmaceuticals, St Davids, PA, USA, and Wake Forest University. This study is supported R01AG033078 and R01ES025888. Petkus and Chen are supported in part by the RF1AG054068. The Women's Health Initiative Study of Cognitive Aging was supported by the Department of Health and Human Services and the National Institute on Aging (N01-AG-1-2106), The research was also supported by the Alzheimer's Disease Research Center at USC (P50A05142)and by the Southern California Environmental Health Sciences Center (5P30ES007048). The WHI program is funded by the National Heart, Lung, and Blood Institute (NIH) through contracts HHSN268201100046C, HHSN268201100001C, HHSN268201100002C, HHSN268201100003C, HHSN268201100004C and HHSN271201100004C.

\section{References}

1. Reynolds K, Pietrzak RH, El-Gabalawy R, et al.: Prevalence of psychiatric disorders in U.S. older adults: findings from a nationally representative survey. World Psychiatry 2015; 14:74-81 [PubMed: 25655161] 
2. Charney DS, Reynolds CF, Lewis L, et al.: Depression and Bipolar Support Alliance consensus statement on the unmet needs in diagnosis and treatment of mood disorders in late life. Arch Gen Psychiatry 2003; 60:664-672 [PubMed: 12860770]

3. Laborde- Lahoz P, El- Gabalawy R, Kinley J, et al.: Subsyndromal depression among older adults in the USA: prevalence, comorbidity, and risk for new-onset psychiatric disorders in late life. Int J Geriatr Psychiatry 2015; 30:677-685 [PubMed: 25345806]

4. Aziz R, Steffens DC. What are the causes of late-life depression? Psychiatr Clin North Am 2013; 36:497-516 [PubMed: 24229653]

5. van Agtmaal MJM, Houben AJHM, Pouwer F, et al.: Association of microvascular dysfunction with late-life depression: a systematic review and meta-analysis. JAMA Psychiatry 2017; 74:729-739 [PubMed: 28564681]

6. Alexopoulos GS, Buckwalter K, Olin J, et al.: Comorbidity of late life depression: an opportunity for research on mechanisms and treatment. Biol Psychiatry 2002; 52:543-558 [PubMed: 12361668]

7. Petkus AJ, Beam CR, Johnson W, et al.: Gene-environment interplay in depressive symptoms: moderation by age, sex, and physical illness. Psychol Med 2017; 47:1836-1847 [PubMed: 28202098]

8. Beard JR, Galea S, Vlahov D. Longitudinal population-based studies of affective disorders: where to from here? BMC Psychiatry 2008; 8:83 [PubMed: 18811958]

9. Fiske A, Wetherell JL, Gatz M. Depression in older adults. Annu Rev Clin Psychol 2009; 5:363-389 [PubMed: 19327033]

10. The Lancet Commission on Pollution and Health. Air pollution and brain health: an emerging issue. Lancet Neurol 2018; 17:103 [PubMed: 29413304]

11. Cacciottolo M, Wang X, Driscoll I, et al.: Particulate air pollutants, APOE alleles and their contributions to cognitive impairment in older women and to amyloidogenesis in experimental models. Transl Psychiatry 2017; 7:e1022 [PubMed: 28140404]

12. Gao R, Ku T, Ji X, et al.: Abnormal energy metabolism and tau phosphorylation in the brains of middle-aged mice in response to atmospheric pm 2.5 exposure. J Environ Sci China 2017; 62:145153 [PubMed: 29289286]

13. Hullmann M, Albrecht C, van Berlo D, et al.: Diesel engine exhaust accelerates plaque formation in a mouse model of Alzheimer's disease. Part Fibre Toxicol 2017; 14:35 [PubMed: 28854940]

14. Fonken LK, Xu X, Weil ZM, et al.: Air pollution impairs cognition, provokes depressive-like behaviors and alters hippocampal cytokine expression and morphology. Mol Psychiatry 2011; 16:987-995 [PubMed: 21727897]

15. Zhang T, Zheng X, Wang X, et al.: Maternal exposure to $\mathrm{PM}_{2.5}$ during pregnancy induces impaired development of cerebral cortex in mice offspring. Int J Mol Sci 2018; 19: E257 [PubMed: 29337904]

16. Liu X, Qian X, Xing J, et al.: Particulate matter triggers depressive-like response associated with modulation of inflammatory cytokine homeostasis and brain-derived neurotrophic factor signaling pathway in mice. Toxicol Sci Off J Soc Toxicol 2018; 164:278-288

17. Kioumourtzoglou M-A, Power MC, Hart JE, et al.: The association between air pollution and onset of depression among middle-aged and older women. Am J Epidemiol 2017; 185:801-809 [PubMed: 28369173]

18. Pun VC, Manjourides J, Suh H. Association of ambient air pollution with depressive and anxiety symptoms in older adults: results from the NSHAP study. Environ Health Perspect 2017; 125:342348 [PubMed: 27517877]

19. Wang Y, Eliot MN, Koutrakis P, et al.: Ambient air pollution and depressive symptoms in older adults: results from the MOBILIZE Boston study. Environ Health Perspect 2014; 122:553-558 [PubMed: 24610154]

20. Kim K-N, Lim Y-H, Bae HJ, et al.: Long-term fine particulate matter exposure and major depressive disorder in a community-based urban cohort. Environ Health Perspect 2016; 124: 1547-1553 [PubMed: 27129131]

21. Resnick SM, Coker LH, Maki PM, et al.: The Women's Health Initiative Study of Cognitive Aging (WHISCA): a randomized clinical trial of the effects of hormone therapy on age-associated cognitive decline. Clin Trials Lond Engl 2004; 1:440-450 
22. Shumaker SA, Reboussin BA, Espeland MA, et al.: The Women's Health Initiative Memory Study (WHIMS): a trial of the effect of estrogen therapy in preventing and slowing the progression of demenia. Control Clin Trials 1998; 19:604-621. [PubMed: 9875839]

23. Shumaker SA, Legault C, Rapp SR, Thal L, Wallace RB, Ockene JK, et al.: Estrogen plus progestin and the incidence of dementia and mild cognitive impairment in post-menopausal women: The Women's Health Initiative Memory Study: A randomized controlled trial. JAMA 2003; 289, 2651-2662. [PubMed: 12771112]

24. Resnick SM, Espeland MA, Jaramillo SA, et al.: Postmenopausal hormone therapy and regional brain volumes: the WHIMS-MRI Study. Neurology 2009; 72:135-142 [PubMed: 19139364]

25. Yesavage JA., Sheikh JI. Geriatric Depression Scale (GDS): Recent evidence and development of a shorter version. Clin Gerontol 1986; 5:165-173

26. Mitchell AJ, Bird V, Rizzo M, et al.: Diagnostic validity and added value of the geriatric depression scale for depression in primary care: a meta-analysis of GDS30 and GDS15. J Affect Disord 2010;125:10-17 [PubMed: 19800132]

27. Robins LN, Helzer JE, Croughan J, et al.: National Institute of Mental Health Diagnostic Interview Schedule. Its history, characteristics, and validity. Arch Gen Psychiatry 1981; 38: 381-389 [PubMed: 6260053]

28. Reyes JM, Xu Y, Vizuete W, et al.: Regionalized $\mathrm{pm}_{2.5}$ community multiscale air quality model performance evaluation across a continuous spatiotemporal domain. Atmos Environ 2017; 148:258-265

29. Whitsel EA, Rose KM, Wood JL, et al.: Accuracy and repeatability of commercial geocoding. Am J Epidemiol 2004; 160:1023-1029 [PubMed: 15522859]

30. American Psychiatric Association. Diagnostic and Statistical Manual of Mental Disorders. Fourth edition. American Psychiatric Association; 1994.

31. Teng EL, Chui HC. The Modified Mini-Mental State (3MS) examination. J Clin Psychiatry 1987; 48:314-318 [PubMed: 3611032]

32. Morris JC, Heyman A, Mohs RC, Hughes JP, van Belle G, Fillenbaum G, et al. The consortium to establish a registry for Alzheimer's disease (CERAD). Part I. Clinical and neuropsychological assessment of Alzheimer's disease. Neurology 1989;39:1159-65. [PubMed: 2771064]

33. Rapp SR, Legault C, Espeland MA, Resnick SM, Hogan PE, Coker LH, et al. Validation of a cognitive assessment battery administered over the telephone. J Am Geriatr Soc 2012; 60:1616-23 [PubMed: 22985137]

34. Chen JC, Wang X, Wellenius GA, et al.: Ambient air pollution and neurotoxicity on brain structure: evidence from women's health initiative memory study. Ann Neurol 2015; 78:466-476 [PubMed: 26075655]

35. Casanova R, Wang X, Reyes J, et al. A voxel-based morphometry study reveals local brain structural alterations associated with ambient fine particles in older women. Front Hum Neurosci 2016; 10:495 [PubMed: 27790103]

36. Geerlings MI, Gerritsen L. Late-life depression, hippocampal volumes, and hypothalamicpituitary-adrenal axis regulation: a systematic review and meta-analysis. Biol Psychiatry 2017; 82:339-350 [PubMed: 28318491]

37. Heckbert SR, Kooperberg C, Safford MM, et al. Comparison of self-report, hospital discharge codes, and adjudication of cardiovascular events in the Women's Health Initiative. Am J Epidemiol 2004; 160:1152-1158 [PubMed: 15583367]

38. Teng EL, Chui HC. The Modified Mini-Mental Status (3MS) examination. The Journal of Clinical Psychiatry 1987; 48: 314-318 [PubMed: 3611032]

39. Proust-Lima C, Philipps V, Liquet B. Estimation of extended mixed models using latent classes and latent processes: The R package lcmm. J Stat Softw 2017; 78

40. Diez Roux AV, Merkin SS, Arnett D, et al.: Neighborhood of residence and incidence of coronary heart disease. N Engl J Med 2001; 345:99-106 [PubMed: 11450679]

41. R: A language and environment for statistical computing. Vienna, Austria: R Foundation for Statistical Computing; 2017.

42. Kim J, Kim H. Demographic and environmental factors associated with mental health: A crosssectional study. Int J Environ Res Public Health 2017;14 
43. Fiest KM, Jette N, Quan H, et al.: Systematic review and assessment of validated case definitions for depression in administrative data. BMC Psychiatry 2014; 14:289 [PubMed: 25322690]

44. Davis KAS, Sudlow CLM, Hotopf M. Can mental health diagnoses in administrative data be used for research? A systematic review of the accuracy of routinely collected diagnoses. BMC Psychiatry 2016; 16

45. Petkus AJ, Espeland MA, Wang X, et al.: Trajectories of depressive symptoms and risk of cognitive decline and dementia in older women Paper presented at the Annual Meeting of the Gerontological Society of America, Boston, MA; 2018.

46. Steffens DC. Late-life depression and the prodromes of dementia. JAMA Psychiatry 2017; 74:673674 [PubMed: 28514459]

47. Patel MJ, Khalaf A, Aizenstein HJ. Studying depression using imaging and machine learning methods. Neuroimage: Clinical 2016; 10: 115-123 [PubMed: 26759786] 


\section{Highlights}

\section{What is the primary question addressed by this study?}

Is late-life exposure to $\mathrm{PM}_{2.5}$ (particulate matter with aerodynamic diameters $<2.5 \mu \mathrm{m}$ ) associated with depressive symptoms in older women without prior depression or dementia and if so, how?

\section{What is the main finding of this study?}

In this 11-year longitudinal study $(\mathrm{n}=1,989)$, residing in locations with higher ambient $\mathrm{PM}_{2.5}$ increased the annually-assessed depressive symptoms, especially among women with sustained mild or moderate symptoms. Dementia risk only partially explained this association, which was independent of MRI-measured brain volumes and small-vesselischemic-disease.

\section{What is the meaning of this study?}

In older women, late-life $\mathrm{PM}_{2.5}$ exposure is a novel environmental risk factor of depressive symptoms, but the neurobiological mechanisms are unclear. 


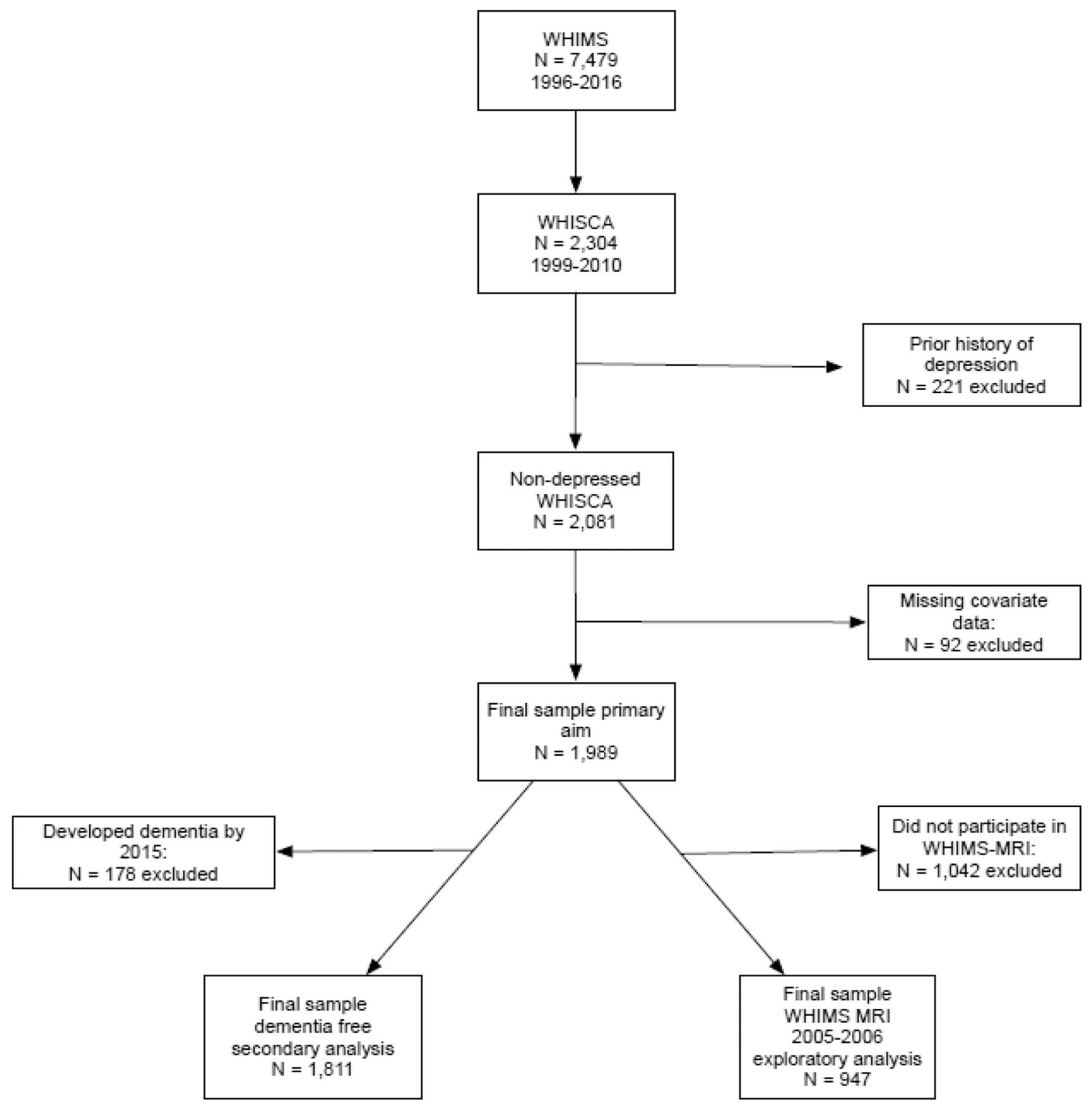

Figure 1.

Flowchart of study participants included in the analyses 
(2A) Mean depressive symptoms by latent class (shaded region denotes $95 \% \mathrm{Cl}$ )
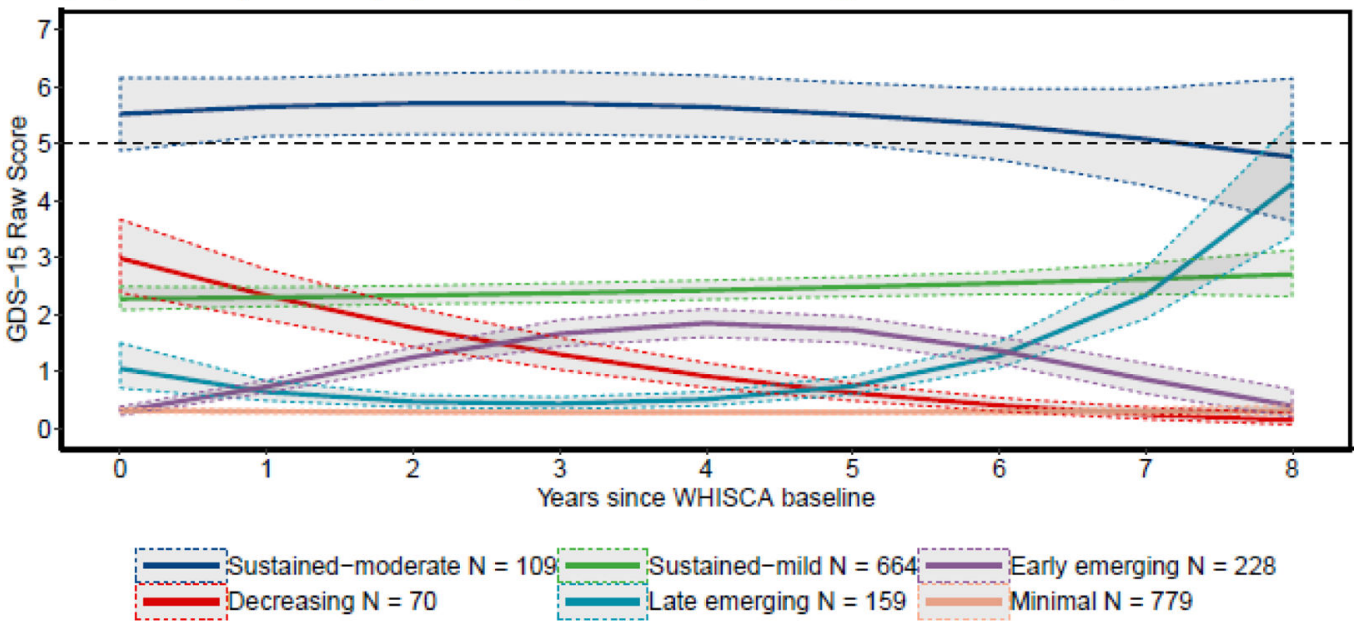

(2B) Mean depressive symptoms by average PM2.5 exposure and latent class

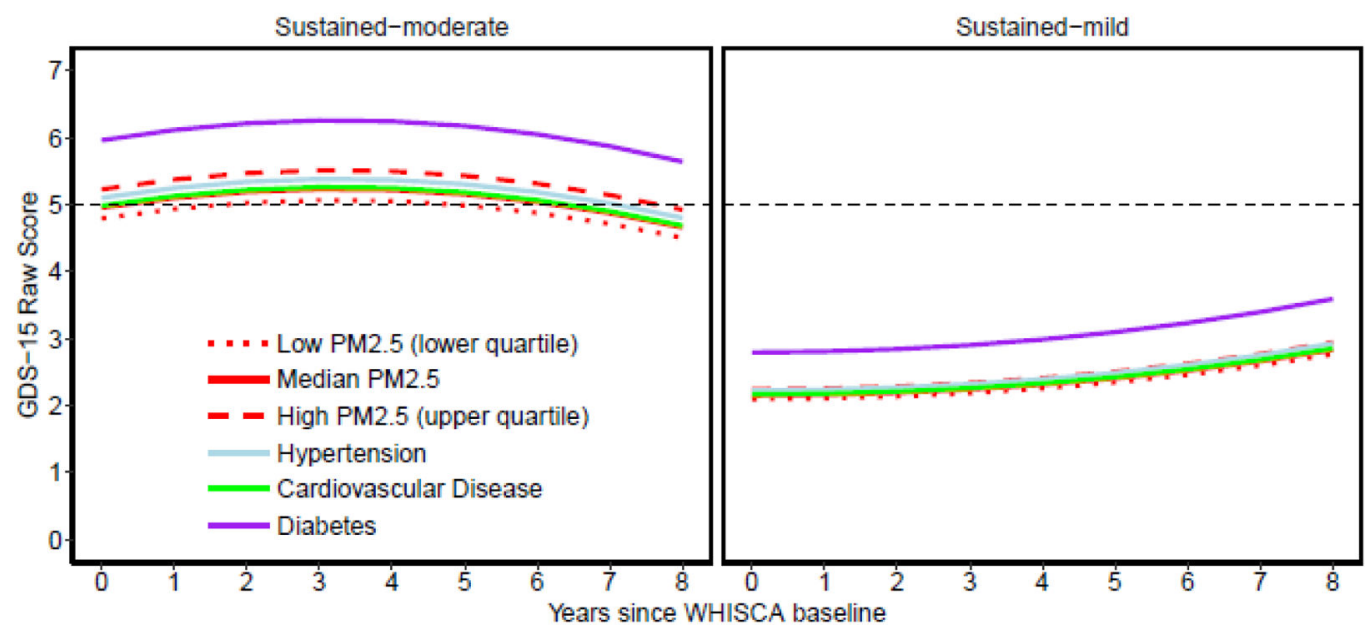

Figure 2.

Graph of the estimated mean score of the 15-item Geriatric Depression Scale with 95\% confidence intervals over time by latent class (panel A). The trajectories of depressive symptoms affected by exposure were depicted over time by high (upper quartile), mean, and low (lower quartile) $\mathrm{PM}_{2.5}$ exposure for women with sustained depressive symptoms (panel B). The reference trajectories of estimated average scores on 15-item Geriatric Depression Scale for women with hypertension, cardiovascular disease, or diabetes were plotted as reference groups with assumed exposures to median $\mathrm{PM}_{2.5}$ levels. A dotted reference line was added at the GDS-15 score of 5 in order to provide a benchmark for clinically significant depressive symptoms. 
Table 1.

Comparison of Estimated $\mathrm{PM}_{2.5}$ Exposure by Baseline Population Characteristics ( $\left.\mathrm{N}=1,989\right)$.

\begin{tabular}{|c|c|c|c|}
\hline \multirow[b]{2}{*}{ Population Characteristics } & \multicolumn{3}{|c|}{$\begin{array}{l}\text { Distribution of time-varying 3-year averagePM }{ }_{2.5}^{a} \\
\qquad \text { Mean } \pm \text { SD }\end{array}$} \\
\hline & $\mathbf{N}$ & ( $25^{\text {th }}$ percentile, median, $75^{\text {th }}$ percentile) & $\mathbf{p}^{b}$ \\
\hline Overall & 1,989 & $12.61 \pm 2.58(10.74,12.03,14.19)$ & \\
\hline Region & & & $<0.01$ \\
\hline Northeast & 418 & $12.18 \pm 1.33(11.1,12.1,13.2)$ & \\
\hline South & 299 & $12.21 \pm 1.77(10.6,11.8,14)$ & \\
\hline Midwest & 772 & $12.85 \pm 2.43(10.7,12.3,15.4)$ & \\
\hline West & 500 & $12.84 \pm 3.69(10.7,11.8,14.9)$ & \\
\hline Ethnicity & & & $<0.01$ \\
\hline African-American & 115 & $15.23 \pm 2.39(13.8,14.7,16.6)$ & \\
\hline Hispanic White & 23 & $12.74 \pm 2.45(11.1,11.9,14.1)$ & \\
\hline White (not Hispanic) & 1802 & $12.41 \pm 2.47(10.7,11.8,13.9)$ & \\
\hline Other or Missing & 49 & $13.81 \pm 3.41(11.4,12.9,16.2)$ & \\
\hline Education & & & 0.02 \\
\hline Less than high school & 89 & $12.48 \pm 2.55(10.9,11.7,14.1)$ & \\
\hline High school & 431 & $12.32 \pm 2.24(10.6,11.7,13.6)$ & \\
\hline More than high school & 1469 & $12.7 \pm 2.67(10.8,12.1,14.3)$ & \\
\hline Employment & & & 0.43 \\
\hline Currently working & 383 & $12.49 \pm 2.61(10.7,12,14)$ & \\
\hline Not working & 190 & $12.79 \pm 2.62(10.8,12.2,14.7)$ & \\
\hline Retired & 1416 & $12.62 \pm 2.56(10.8,12,14.2)$ & \\
\hline Income (USD) & & & $<0.01$ \\
\hline$<9,999$ & 422 & $12.34 \pm 2.57(10.6,11.5,14.1)$ & \\
\hline $10,000-34,999$ & 625 & $12.58 \pm 2.51(10.7,12.1,14.1)$ & \\
\hline $35,000-49,999$ & 430 & $12.6 \pm 2.53(10.7,12,14)$ & \\
\hline $50,000-74,999$ & 277 & $12.82 \pm 2.71(11,12.2,14.2)$ & \\
\hline 75,000 or more & 176 & $13.19 \pm 2.75(11,12.5,14.9)$ & \\
\hline Don't know & 59 & $12.27 \pm 2.3(10.7,11.9,13.5)$ & \\
\hline \multicolumn{4}{|l|}{ Lifestyle } \\
\hline Smoking status & & & 0.44 \\
\hline Never smoked & 1106 & $12.64 \pm 2.61(10.7,12,14.3)$ & \\
\hline Past smoker & 775 & $12.61 \pm 2.51(10.8,12.1,14)$ & \\
\hline Current Smoker & 108 & $12.31 \pm 2.72(10.5,11.7,14.1)$ & \\
\hline Alcohol use & & & 0.07 \\
\hline Non-drinker & 246 & $12.99 \pm 2.7(10.7,12.5,14.8)$ & \\
\hline Past drinker & 347 & $12.57 \pm 2.54(10.7,12,14.4)$ & \\
\hline Less than 1 drink per day & 1148 & $12.52 \pm 2.55(10.7,12,13.9)$ & \\
\hline More than 1 drink per day & 248 & $12.69 \pm 2.61(10.9,12,14.2)$ & \\
\hline
\end{tabular}




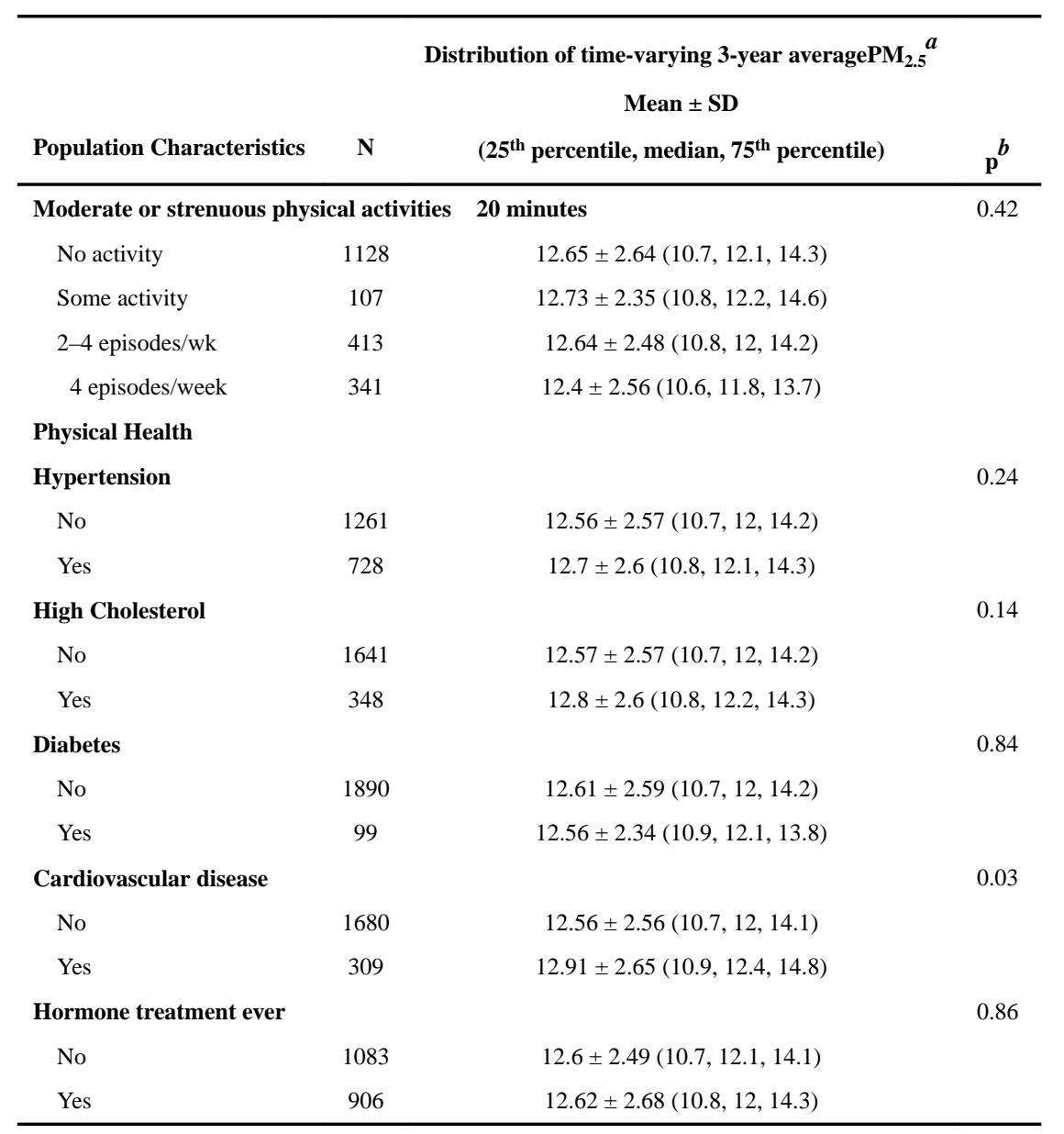

${ }^{a}{ }_{\mathrm{PM}} 2.5$ represents the distribution of the individual-level summary of all time-varying 3-year exposures aggregated from the daily exposure levels estimated at each residential location using the spatiotemporal model.

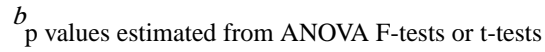


Table 2.

Comparison of Baseline Population Characteristics by Latent Class ${ }^{a}$ of Depressive Symptoms in the Women's Health Initiative Study on Cognitive Aging $(\mathrm{N}=1,989)$.

\begin{tabular}{|c|c|c|c|c|c|c|c|}
\hline $\begin{array}{l}\text { Population } \\
\text { Characteristics }\end{array}$ & $\begin{array}{c}\text { Resilient } \\
\mathrm{N}=779 \\
\text { Mean (sd) } \\
\quad \text { or } \\
\%^{b}(\mathrm{~N})\end{array}$ & $\begin{array}{c}\begin{array}{c}\text { Early } \\
\text { emerging }\end{array} \\
\mathrm{N}=228 \\
\text { Mean (sd) } \\
\text { or } \\
\%^{b}(\mathrm{~N})\end{array}$ & $\begin{array}{l}\text { Late emerging } \\
\qquad \begin{array}{c}\mathrm{N}=159 \\
\text { Mean (sd) } \\
\text { or } \\
\%^{b}(\mathrm{~N})\end{array}\end{array}$ & $\begin{array}{l}\text { Sustained-Mild } \\
\qquad \begin{array}{c}\mathrm{N}=644 \\
\text { Mean (sd) } \\
\text { or } \\
\%^{b}(\mathrm{~N})\end{array}\end{array}$ & $\begin{array}{c}\text { Decreasing } \\
\begin{array}{c}\mathrm{N}=70 \\
\text { Mean (sd) } \\
\text { or } \\
\%^{b}(\mathrm{~N})\end{array}\end{array}$ & $\begin{array}{c}\text { Sustained- } \\
\text { Moderate } \\
\text { N = 109 } \\
\text { Mean (sd) } \\
\text { or } \\
\%^{b} \text { (N) }\end{array}$ & $\mathrm{p}^{c}$ \\
\hline Age (years) & $73.00(3.56)$ & $73.37(3.82)$ & $72.72(3.45)$ & $73.83(4.02)$ & $72.89(3.61)$ & $73.87(3.71)$ & $<.01$ \\
\hline GDS-15 ${ }^{d}$ & $.25(.58)$ & $.09(.3)$ & $1.36(1.43)$ & $2.12(1.57)$ & $3.09(2.25)$ & $5.79(2.5)$ & $<.01$ \\
\hline Region & & & & & & & .08 \\
\hline Northeast & $39 \%(163)$ & $10 \%(43)$ & $8 \%(33)$ & $34 \%(144)$ & $3 \%(12)$ & $6 \%(23)$ & \\
\hline South & $37 \%(110)$ & $12 \%(37)$ & $10 \%(31)$ & $33 \%(100)$ & $3 \%(9)$ & $4 \%(12)$ & \\
\hline Midwest & $40 \%(310)$ & $14 \%(109)$ & $8 \%(59)$ & $29 \%(220)$ & $4 \%(30)$ & $6 \%(44)$ & \\
\hline West & $39 \%(196)$ & $8 \%(39)$ & $7 \%(36)$ & $36 \%(180)$ & $4 \%(19)$ & $6 \%(30)$ & \\
\hline Ethnicity & & & & & & & $<.01$ \\
\hline African-American & $34 \%(39)$ & $10 \%(11)$ & $6 \%(7)$ & $36 \%(41)$ & $3 \%(3)$ & $12 \%(14)$ & \\
\hline Hispanic White & $17 \%(4)$ & $17 \%(4)$ & $4 \%(1)$ & $35 \%(8)$ & $4 \%(1)$ & $22 \%(5)$ & \\
\hline White (not Hispanic) & $40 \%(713)$ & $12 \%(212)$ & $8 \%(150)$ & $32 \%(577)$ & $4 \%(64)$ & $4 \%(86)$ & \\
\hline Other or Missing & $47 \%(23)$ & $2 \%(1)$ & $1 \%(1)$ & $37 \%(18)$ & $4 \%(2)$ & $8 \%(4)$ & \\
\hline Education & & & & & & & $<.01$ \\
\hline Less than high school & $24 \%(21)$ & $16 \%(14)$ & $1 \%(1)$ & $45 \%(40)$ & $3 \%(3)$ & $11 \%(10)$ & \\
\hline High school & $38 \%(163)$ & $11 \%(46)$ & $9 \%(38)$ & $32 \%(137)$ & $4 \%(16)$ & $7 \%(31)$ & \\
\hline More than high school & $41 \%(595)$ & $11 \%(168)$ & $8 \%(120)$ & $32 \%(467)$ & $3 \%(51)$ & $5 \%(68)$ & \\
\hline Employment & & & & & & & .01 \\
\hline Currently working & $39 \%(148)$ & $10 \%(37)$ & $12 \%(47)$ & $32 \%(122)$ & $3 \%(11)$ & $5 \%(18)$ & \\
\hline Not working & $40 \%(76)$ & $10 \%(18)$ & $2 \%(4)$ & $40 \%(76)$ & $4 \%(7)$ & $5 \%(9)$ & \\
\hline Retired & $39 \%(555)$ & $12 \%(173)$ & $7 \%(108)$ & $32 \%(446)$ & $4 \%(52)$ & $6 \%(82)$ & \\
\hline \multicolumn{8}{|l|}{ Annual income } \\
\hline (dollars) & & & & & & & $<.01$ \\
\hline$<9,999$ & $31 \%(129)$ & $12 \%(50)$ & $8 \%(32)$ & $39 \%(165)$ & $2 \%(9)$ & $9 \%(37)$ & \\
\hline $10,000-34,999$ & $38 \%(235)$ & $10 \%(65)$ & $8 \%(52)$ & $36 \%(224)$ & $3 \%(18)$ & $5 \%(31)$ & \\
\hline $35,000-49,999$ & $43 \%(185)$ & $13 \%(58)$ & $8 \%(34)$ & $26 \%(110)$ & $4 \%(18)$ & $6 \%(25)$ & \\
\hline $50,000-74,999$ & $48 \%(132)$ & $9 \%(26)$ & $10 \%(28)$ & $24 \%(66)$ & $5 \%(13)$ & $4 \%(12)$ & \\
\hline 75,000 or more & $45 \%(79)$ & $14 \%(25)$ & $5 \%(9)$ & $31 \%(55)$ & $4 \%(7)$ & $1 \%(1)$ & \\
\hline Don't know & $32 \%(19)$ & $7 \%(4)$ & $7 \%(4)$ & $41 \%(24)$ & $8 \%(5)$ & $5 \%(3)$ & \\
\hline \multicolumn{8}{|l|}{ Lifestyle } \\
\hline Smoking status & & & & & & & 0.55 \\
\hline Never smoked & $40 \%$ (447) & $12 \%(130)$ & $8 \%(89)$ & $30 \%(337)$ & $3 \%(38)$ & $6 \%(65)$ & \\
\hline Past smoker & $38 \%(292)$ & $12 \%(91)$ & $8 \%(62)$ & $34 \%(266)$ & $3 \%(28)$ & $5 \%(36)$ & \\
\hline
\end{tabular}




\begin{tabular}{|c|c|c|c|c|c|c|c|}
\hline $\begin{array}{l}\text { Population } \\
\text { Characteristics }\end{array}$ & $\begin{array}{c}\text { Resilient } \\
\text { N }=779 \\
\text { Mean (sd) } \\
\text { or } \\
\%^{b}(\mathrm{~N})\end{array}$ & $\begin{array}{c}\begin{array}{c}\text { Early } \\
\text { emerging }\end{array} \\
\mathrm{N}=228 \\
\text { Mean (sd) } \\
\text { or } \\
\%^{b}(\mathrm{~N})\end{array}$ & $\begin{array}{l}\text { Late emerging } \\
\begin{array}{c}\mathrm{N}=159 \\
\text { Mean (sd) } \\
\text { or } \\
\%^{b}(\mathrm{~N})\end{array}\end{array}$ & $\begin{array}{l}\text { Sustained-Mild } \\
\qquad \begin{array}{c}\mathrm{N}=644 \\
\text { Mean (sd) } \\
\text { or } \\
\%^{b}(\mathrm{~N})\end{array}\end{array}$ & $\begin{array}{l}\text { Decreasing } \\
\qquad \begin{array}{c}\mathrm{N}=70 \\
\text { Mean (sd) } \\
\text { or } \\
\%^{b}(\mathrm{~N})\end{array}\end{array}$ & $\begin{array}{c}\text { Sustained- } \\
\text { Moderate } \\
\text { N }=109 \\
\text { Mean (sd) } \\
\text { or } \\
\%^{b}(\mathrm{~N})\end{array}$ & $\mathrm{p}^{c}$ \\
\hline Current Smoker & $37 \%(40)$ & $6 \%(7)$ & $7 \%(8)$ & $38 \%(41)$ & $4 \%(4)$ & $7 \%(8)$ & \\
\hline Alcohol use & & & & & & & 0.03 \\
\hline Non-drinker & $42 \%(103)$ & $14 \%(34)$ & $8 \%(20)$ & $29 \%(71)$ & $4 \%(11)$ & $3 \%(7)$ & \\
\hline Past drinker & $32 \%(112)$ & $9 \%(32)$ & $10 \%(33)$ & $39 \%(134)$ & $3 \%(10)$ & $7 \%(26)$ & \\
\hline Less than 1 drink / day & $39 \%(449)$ & $12 \%(137)$ & $8 \%(89)$ & $32 \%(364)$ & $4 \%(42)$ & $6 \%(67)$ & \\
\hline More than 1 drink / day & $46 \%(115)$ & $10 \%(25)$ & $7 \%(17)$ & $30 \%(75)$ & $3 \%(7)$ & $4 \%(9)$ & \\
\hline Moderate or strenuous ph & sical activities & $\geq 20$ minutes & & & & & $<.01$ \\
\hline No activity & $35 \%(394)$ & $10 \%(113)$ & $8 \%(93)$ & $37 \%(415)$ & $3 \%(35)$ & $7 \%(78)$ & \\
\hline Some activity & $37 \%(40)$ & $17 \%(18)$ & $12 \%(13)$ & $25 \%(27)$ & $3 \%(3)$ & $6 \%(6)$ & \\
\hline 2-4 episodes/wk & $44 \%(180)$ & $13 \%(53)$ & $4 \%(18)$ & $30 \%(125)$ & $5 \%(19)$ & $4 \%(18)$ & \\
\hline ×pisodes/week & $48 \%(165)$ & $13 \%(44)$ & $10 \%(35)$ & $23 \%(77)$ & $4 \%(13)$ & $2 \%(7)$ & \\
\hline Physical Health & & & & & & & \\
\hline Hypertension & & & & & & & $<.01$ \\
\hline No & $42 \%(532)$ & $11 \%(143)$ & $8 \%(98)$ & $29 \%(368)$ & $4 \%(52)$ & $5 \%(68)$ & \\
\hline Yes & $34 \%(247)$ & $12 \%(85)$ & $8 \%(61)$ & $38 \%(276)$ & $2 \%(18)$ & $6 \%(41)$ & \\
\hline High Cholesterol & & & & & & & .53 \\
\hline No & $40 \%(657)$ & $11 \%(187)$ & $8 \%(130)$ & $32 \%(526)$ & $3 \%(54)$ & $5 \%(87)$ & \\
\hline Yes & $35 \%(122)$ & $12 \%(41)$ & $8 \%(29)$ & $34 \%$ (118) & $5 \%(16)$ & $6 \%(22)$ & \\
\hline Diabetes & & & & & & & $<.01$ \\
\hline No & $40 \%(753)$ & $12 \%(224)$ & $8 \%(151)$ & $32 \%(599)$ & $4 \%(69)$ & $5 \%(94)$ & \\
\hline Yes & $26 \%(26)$ & $4 \%(4)$ & $8 \%(8)$ & $45 \%(45)$ & $1 \%(1)$ & $15 \%(15)$ & \\
\hline Cardiovascular disease & & & & & & & .01 \\
\hline No & $41 \%(685)$ & $11 \%(187)$ & $8 \%(133)$ & $31 \%(527)$ & $4 \%(62)$ & $5 \%(86)$ & \\
\hline Yes & $30 \%(94)$ & $13 \%(41)$ & $8 \%(26)$ & $38 \%(117)$ & $3 \%(8)$ & $7 \%(23)$ & \\
\hline \multicolumn{8}{|l|}{ Hormone treatment } \\
\hline ever & & & & & & & .30 \\
\hline No & $41 \%(447)$ & $11 \%(123)$ & $8 \%(89)$ & $30 \%(329)$ & $4 \%(38)$ & $5 \%(57)$ & \\
\hline Yes & $37 \%(332)$ & $12 \%(105)$ & $8 \%(70)$ & $35 \%(315)$ & $4 \%(32)$ & $6 \%(52)$ & \\
\hline \multicolumn{8}{|l|}{ Baseline exposure } \\
\hline $\mathrm{PM}_{2.5}$ (3-year average) & $12.78(2.4)$ & $12.83(2.4)$ & $12.64(2.16)$ & $12.66(2.46)$ & $12.56(2.38)$ & $13.14(2.52)$ & .42 \\
\hline
\end{tabular}

${ }^{a}$ Group membership estimated from the latent class model that includes the initial level of depressive symptoms with both fixed effects and random intercept, linear and quadratic change of follow-up time, initial WHISCA age, and attrition (yes/no if participant dropped out at the subsequent assessment time) to account for heterogeneity in the longitudinal profiles of depressive symptoms.

$b_{\text {Percentage reported above represent row percentages. }}$

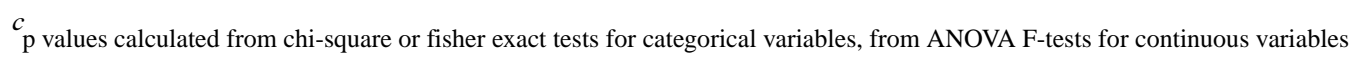

${ }^{d}$ GDS-15 = Geriatric Depression Scale-15

Am J Geriatr Psychiatry. Author manuscript; available in PMC 2020 October 01. 
Table 3.

Effect of Time-Varying 3-Year Average $\mathrm{PM}_{2.5}$ Exposure on Depressive Symptoms Measured by the 15-Item Geriatric Depression Scale in the Women's Health Initiative Study of Cognitive Aging ${ }^{a}$

\begin{tabular}{|c|c|c|c|c|c|c|c|}
\hline & \multicolumn{7}{|c|}{$\mathbf{P M}_{2.5}$ Effect Estimate } \\
\hline & \multirow{2}{*}{\multicolumn{3}{|c|}{$\begin{array}{c}\text { Full sample } \\
\mathrm{N}=\mathbf{1 , 9 8 9}\end{array}$}} & & \multirow{2}{*}{\multicolumn{3}{|c|}{$\begin{array}{c}\text { Dementia-free sample } \\
\qquad \mathbf{N}=\mathbf{1 , 8 1 1}\end{array}$}} \\
\hline & & & & & & & \\
\hline & $\beta^{b}$ & $\mathrm{SE}^{c}$ & $\mathbf{p}$ & & $\beta^{b}$ & $\mathrm{SE}^{c}$ & $\mathbf{p}$ \\
\hline \multicolumn{8}{|l|}{ Model 1:Global main effect } \\
\hline $\begin{array}{l}\text { Exposure effect estimate common to all } \\
\text { classes }\end{array}$ & .043 & .021 & .039 & $\begin{array}{l}\text { Exposure effect estimate common to all } \\
\text { classes }\end{array}$ & .038 & .014 & .006 \\
\hline \multicolumn{8}{|l|}{ Model 2: Class-specific exposure effect } \\
\hline Minimal $(n=802)$ & .021 & .026 & .426 & Minimal $(n=737)$ & .014 & .020 & .489 \\
\hline Early-emerging $(\mathrm{n}=214)$ & -.005 & .124 & .968 & Early-emerging $(\mathrm{n}=199)$ & -.008 & .042 & .855 \\
\hline Late-emerging $(\mathrm{n}=158)$ & .168 & .106 & .113 & Late-emerging $(\mathrm{n}=141)$ & .175 & .050 & $<.001$ \\
\hline Sustained-mild $(n=626)$ & .096 & .042 & .023 & Sustained-mild $(\mathrm{n}=568)$ & .086 & .026 & $<.001$ \\
\hline Decreasing $(n=67)$ & -.141 & .104 & .176 & Decreasing $(n=62)$ & -.078 & .061 & .201 \\
\hline Sustained-moderate $(\mathrm{n}=122)$ & .171 & .076 & .024 & Sustained-moderate $(n=104)$ & .151 & .058 & .009 \\
\hline
\end{tabular}

${ }^{a}$ All models adjust for age at WHISCA baseline, race/ethnicity, attrition, geographic region of residence, education, household income, employment status, baseline global cognitive ability, lifestyle factors (smoking, alcohol use, physical activities) and clinical characteristics (use of hormone treatment; hypercholest erolemia, hypertension, diabetes, and history of cardiovascular disease).

$b_{\beta}=$ the average increase in transformed 15 -item Geriatric Depression Scale score per increase of one interquartile range $\left(3.45 \mu \mathrm{g} / \mathrm{m}^{3}\right)$ of timevarying 3-year average exposure to $\mathrm{PM}_{2.5}$

$c_{\mathrm{SE}}=$ the standard error of the estimated effect of $\mathrm{PM}_{2.5}$ on 15-item Geriatric Depression Scale.

Bolded estimates denote $\mathrm{p}<.05$ 